\title{
Green Synthesis of CuO Nanoparticles and its Application on Toxicology Evaluation
}

\author{
Santhoshkumar Jayakodi (D), Venkat Kumar Shanmugam * (D) \\ School of Biosciences and Technology, VIT University, Vellore - 632014, TN \\ * Correspondence: venkatkumars@ vit.ac.in;
}

Scopus Author ID 51462272000

Received: 20.04.2020; Revised: 10.05.2020; Accepted: 11.05.2020; Published: 13.05.2020

\begin{abstract}
This study aims to understand the major effects of Copper oxide nanoparticles on toxic and fish pathogens by using a green method. Safer methods like the usage of microorganisms prove to be eco-friendly and extremely practical than the regular physical and chemical methods. The characters and features of the $\mathrm{CuO}$ particles were understood by using analytical techniques like XRD, UV-vis spectroscopy, FTIR, SEM-EDX, TEM and AFM. Further analysis showed that the spherical particle size was around $100 \mathrm{~nm}$. When prepared in pure water to zebrafish, with a $96 \mathrm{~h} \mathrm{LC} \mathrm{L}_{50}$ concentration of $67.61 \mathrm{mg} / \mathrm{L}$. The possibility to evaluate hatching time in the $96 \mathrm{~h}$ acute embryo toxicity test seems to be an advantage against that of the 96-hour toxicity since this toxicity was a life stage-dependent.
\end{abstract}

Keywords: Zebrafish; Aeromonas hydrophila; Nanotoxicology; copper oxide; nanoparticles.

(C) 2020 by the authors. This article is an open access article distributed under the terms and conditions of the Creative Commons Attribution (CC BY) license (https://creativecommons.org/licenses/by/4.0/).

\section{Introduction}

The use of nanotechnology has increased due to its ability to modify the characteristics of the materials at nano levels. At the nanoscale, the materials exhibit various properties that are extremely unique in comparison to the macroscale or the microscale [1]. Due to their astonishingly unique properties, it is best to say that nanomaterials are used vastly in many fields of research [2]. There has been a sudden demand for the use of nanomaterials due to their extremely optimal properties in academics field [3]. Copper Oxide nanoparticles properties of semi conductivity at high temperatures, photovoltaic properties and in general antimicrobial properties are said to be of novel use in nanotechnology [4]. CuO nanoparticles additionally have different innovation applications, for example, catalysis [5], batteries because of the high electrochemical limit [6], and gas sensors [7]. Nanoparticles of Metal-oxide are getting consideration in a substantial assortment of biomedical applications like antimicrobials [8], antibacterial [9], antitumor activity [10] and anticancer movement [11]. Global demand for Copper Oxide Nanoparticles (CuONPs) in comparison to gold and silver is due to the fact that they are cost-effective and extremely easy to procure them [12]. CuONPs have aroused a lot of researchers to think about the application of such intriguing properties since due to their inert nature [13]. They are heterogeneous crystals that exhibit anti-microbial and anti-oxidant properties [14]. They are also extremely useful in the biomedical field for imaging and conveyance [15]. In contrast to expensive chemical substances, nanomaterials are exceptionally compatible with biomolecules and can be used for treating cancer [16].

Copper Nanoparticles are used to mainly control bacterial infestations [17], antifungal [18], and used for cancer treatment [19]. Biological synthesis is viewed as a kind of compound 
strategy, in spite of the fact that it creates nanoparticles by decreasing metallic particles by biomolecules exhibit in plants [20], plant extracts, organic products [21], marine green growth [22], microbes [23] and yeast [24]. Zebrafish are widely used in many fields such as pharmacology and genetics because it is a promising animal model with high breeding and household costs, transparent embryos and high levels of genetic homology with humans [25]. Previous studies have reported that the ions released from $\mathrm{CuO}-\mathrm{NP}$ are toxic, although to the best of our knowledge we have few studies to explain that CuO-NP is low toxicity [26]. This leads to the use of large quantities of toxic effects, which results in humans being exposed to higher levels of CuO-NP [27]. Therefore, it is imperative to check the toxic effects of $\mathrm{CuO}-\mathrm{NP}$ at very low concentrations.

Although the biosynthesis of copper oxide nanoparticles by Aeromonas hydrophila as previously been reported, the potential of microorganisms as biological materials for the synthesis of nanoparticles is not yet to be fully explored. The biosynthesized CuONPs have been used to find out the biomedicinal properties in zebrafish using embryo toxicity study. Our present study aims and focused only on toxicity analysis by green synthesis method and embryotoxicity in zebrafish model.

\section{Materials and Methods}

\subsection{Culturing of Aeromonas hydrophila.}

A rod-shaped, gram-negative bacteria-Aeromonas hydrophila causes ailments in fishes present in brackish water. These fishes are used the production of bacterial cultures of nanoparticles like Copper Sulphate and Calcium Carbonate. A nutrient broth was used to grow the bacteria which included essential nutrients like carbohydrates, salts, vitamins, mineral, beef extract and yeast extract. For a time period of $24 \mathrm{~h}$ at $30^{\circ} \mathrm{C}$, the microorganisms were inoculated in a shaker. The intracellular process of synthesis was done in which the precursor was added followed by centrifugation. Cell harvesting was done by centrifugation at $10000 \mathrm{rpm}$ for 15 $\min$.

\subsection{Biosynthesis of copper oxide nanoparticles.}

CuONPs are biosynthesised using bacteria Aeromonas hydrophila. The cells after harvesting, the precursor was added to the cell-free supernatant, where Copper Sulphate is the precursor. $0.024 \mathrm{~g}$ of Copper Sulphate (molecular weight of $159.6 \mathrm{~g} / \mathrm{mol}$ ) was added.
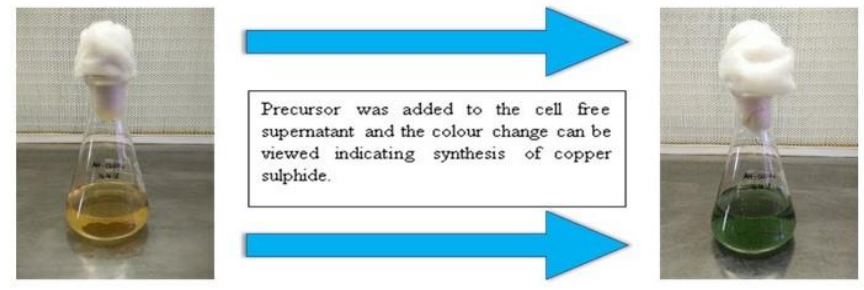

Figure 1. Biosynthesis of copper oxide nanoparticles.

In figure 1, we can observe a colour change from yellow to green after the addition of precursor to the supernatant which indicates the reduction of $\mathrm{Cu}$ (II) to $\mathrm{Cu} \mathrm{Np}$ (Copper Nano Particles) by using the enzymes present in the bacteria. The culture was assessed once every 2 hours. The culture was then again incubated for a time period of 24 hours in a shaker after adding a precursor again. This was followed by centrifugation at $10000 \mathrm{rpm}$ for $15 \mathrm{mins}$ where the pellets where collected contains nanoparticles. The pellets collected where kept in a hot air 
oven on a watch glass to make it dry. After the sample was powdered and dried, the sample was studied by techniques like XRD, FTIR, AFM, SEM and TEM to understand its characteristics. The characters observed were proven to induce antimicrobial activity.

\subsection{Experimental methods.}

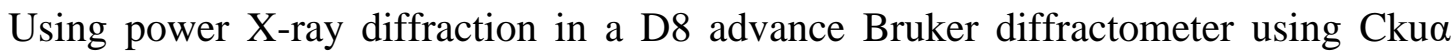
radiation, the credentials of the crystal structures were observed where the diffraction angle was verified in the $2 \theta$ ranged among $38^{\circ}-80^{\circ}$. Using Debye Scherrer formula, the crystallite size was found and using FEI quanta 200F instrument and the elemental analysis. By using energy dispersive X-ray analysis with a spectrometer, the chemical conformation of the sample was identified. UV-vis absorption spectroscopy model no: 2450 with wavelength range among 200-800 nm, the optical property of the samples were identified along with the optical bandgap.

\subsection{Zebrafish embryotoxicity (mortality and hatchability rate).}

Slight alterations of exposures were conducted in accordance with the OECD guideline $[28,29]$. For a short time, viable zebrafish embryos $(<6 \mathrm{hpf})$ were used, and well-fertilized embryos at a comparable developmental stage stayed collected for exposures. Embryos that were white and cloudy are unfertilized which are undesirable here and were cast off [30]. This followed by transferring carefully the embryos to wells of U-bottom 9-well plates and incubation of these embryos in $5 \mathrm{ml}$ solution for $96 \mathrm{~h}$. The tested concentrations for each of the two $\mathrm{CuO}$ forms were 10, 20, 40, 60 and $80 \mu \mathrm{g} / \mathrm{L} \mathrm{CuONPs.} \mathrm{The} \mathrm{hatching} \mathrm{and} \mathrm{mortality} \mathrm{of} \mathrm{the}$ embryos were assessed keenly during the periods of careful and precise exposure. Regular intervals of incubation of time periods like $24,48,72$ and $96 \mathrm{~h}$ were used to verify the mortality of embryos. The percentage of dead embryos at each point of the incubation was stated as death. Hatching success was articulated as the percentage of hatched embryos after $97 \mathrm{~h}$. The examination was carried out with their repeats; each consisting of 8 exposed embryos or 16 for controls.

\section{Results and Discussion}

\subsection{Powdered X-ray diffraction.}

Figure 2 represents the altered form of copper sulphate crystals in the powdered X-ray diffraction form, which was produced by biosynthesis. The obtained copper sulphate samples could be indexed to the cubic structure with the space group. The fine crystalline phase that exists in the nanoparticles were revealed through the intense peaks from the XRD patterns also the standard JCPDS data card no: 05-0667 matches with this [31,32]. The purity of the monophasic Nanocrystalline compounds from the XRD pattern confirms that no extra peaks were identified.

The standard particle dimensions calculated from the Debye-Scherrer formula,

$$
\mathrm{D}=\frac{0.9 \lambda}{\beta \cos \theta}
$$

where $\lambda$ is the $X$-ray wavelength, $\beta$ is the full width half maximum intensity value and $\theta$ is the Bragg's angle. 
The average particle size calculated as $31 \mathrm{~nm}$. Using the XRD data the lattice parameter and various mechanical parameters such as crystallite size, disruption density, and lattice strain, the surface area also were calculated which shown in Table 1.

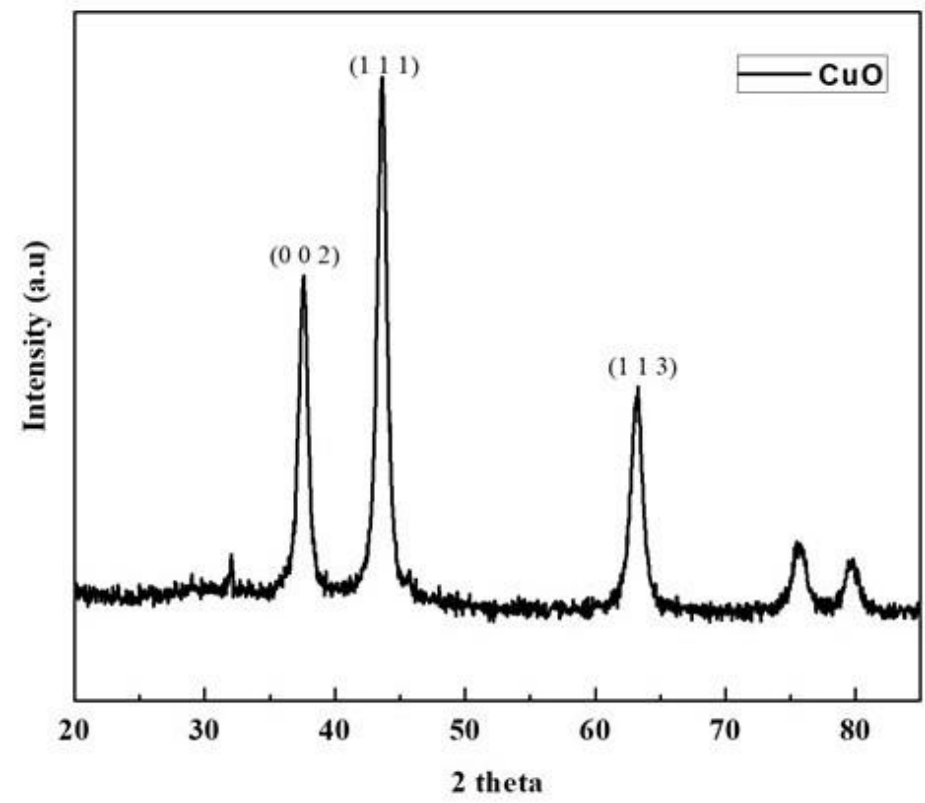

Figure 2. Powder XRD patterns of Copper oxide.

\subsection{Morphology and elemental composition analysis.}

Figure $3 \mathrm{a}, \mathrm{b}$ shows the surface morphology of the prepared samples; also, it shows the SEM images of copper sulphate synthesized by Aeromonas hydrophila crystalline powders at a different magnification at $2 \mu \mathrm{m}$ and $200 \mathrm{~nm}$ respectively. It visibly shows that the particles are minor and practically spherical which is free from the cluster.

Figure 3c shows the chemical structure of biosynthesized the EDX spectrum revealed $\mathrm{CuO}$ NPs. Since the spectrum, strong peaks detected and small peak observed from O elements. Copper oxide nanoparticles aggregated rapidly, and much of the mass of added copper oxide was present as agglomerates greater than $0.5 \mu \mathrm{m}$ in diameter Figure 3 d,e. However, many particles with a diameter of less than $100 \mathrm{~nm}$ were present in a spherical shape [33].

Figure 4a shows progress of biosynthesis of Copper oxide NPs as a function of time. The UV-vis spectra indicate the broth when added in the $\mathrm{CuSO}_{4}$ aqueous solution initiated the synthesize Copper oxide NPs till $4 \mathrm{~h}$ as is evident from the peaks obtained at different time intervals at $298 \mathrm{~nm}$. The spectrum of pure copper oxide nanoparticles shows the band edgeabsorption peak which originates from being at $323 \mathrm{~nm}$ represented in Figure 4b. In UV-Vis, to promote electrons to higher energy orbitals high-energy electromagnetic radiation in the wavelength range of $200-600 \mathrm{~nm}$ is utilized. The essential absorption, which matches to electron excitation from the valence band to the conduction band, can be used to fix the value of the visual bandgap. The association between the absorption coefficients $\alpha$ and the incident photon energy ho can write as

$$
(\alpha h \vartheta)=A(h \vartheta-E g)^{n}
$$

Where $\mathrm{A}$ is a constant and Eg the bandgap in electron volt $(\mathrm{eV})$. The equation using, the calculated value of the bandgap energy for the synthesized $\mathrm{CuO}$ nanoparticle is $2.0 \mathrm{eV}$ represented in Figure 4c. The bandgap increases with the decrease in the particle size, which is reported in previous literature [34,35]. The formation of nanoparticles monitored. Primarily there was a colour change when the precursor added to the cell-free supernatant. This sample 
indicates that there are some changes in the size and synthesis of nanoparticle has occurred. When the copper sulphate added to the broth, which was centrifuged to get cell-free broth changes from yellow to green due to the synthesis of $\mathrm{Cu}$ nanoparticles. Wavelength took from $250-500 \mathrm{~nm}$ at the one-hour interval. The peak absorbance was at $298 \mathrm{~nm}$, which implies that at that particular peak copper was synthesized in high amount. There is a shift of peak due to the addition of broth in copper nanoparticles. The detected increasing bandgap could be credited to the presence of intra gap states and quantum imprisonment effect.

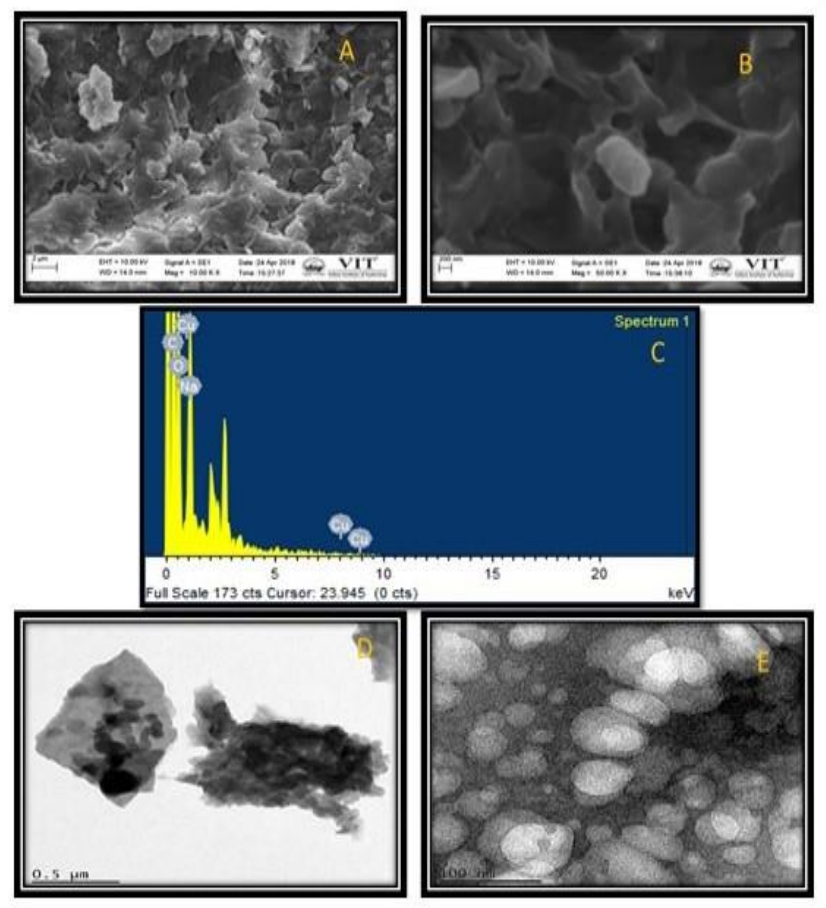

Figure 3. (A, B) SEM images copper nanoparticle synthesized by Aeromonas hydrophila EDX spectrum (C) for copper oxide nanoparticle and (D, E) HRTEM images of $\mathrm{CuO}$ morphologies.
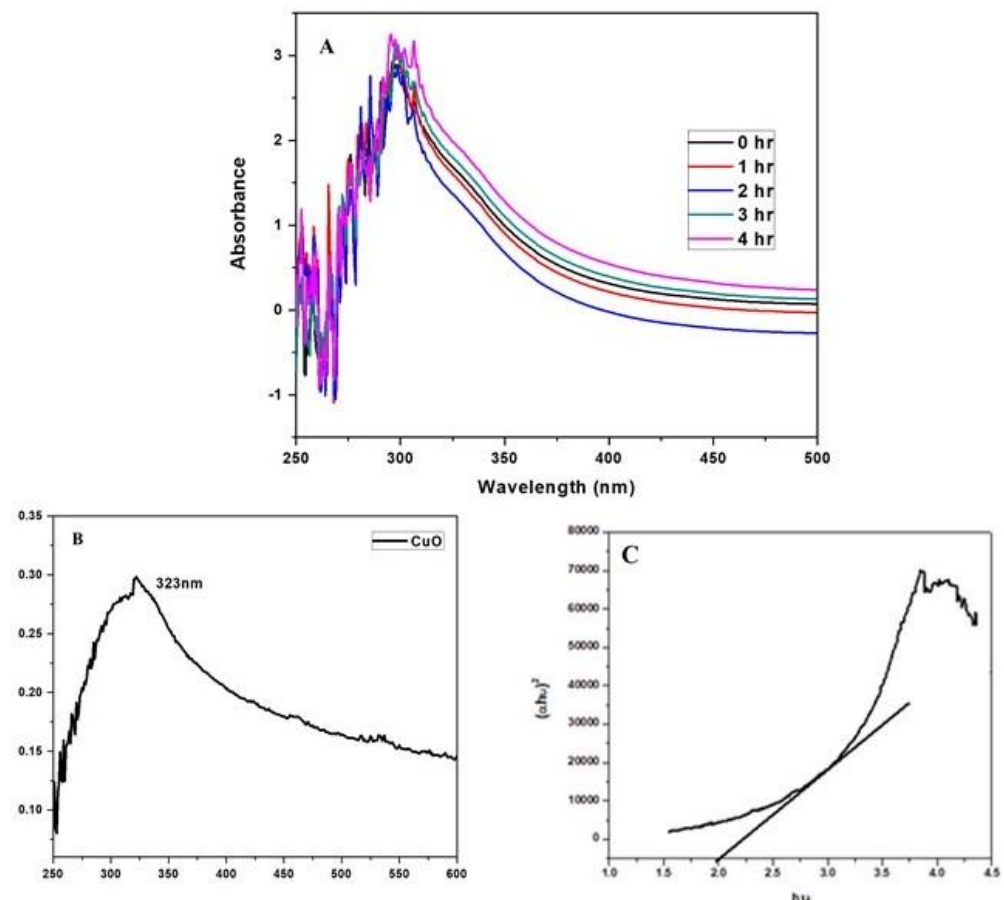

Figure 4. (a) UV-visible spectra of copper oxide nanoparticles synthesized from Aeromonas hydrophila, (b) spectra of pure copper oxide nanoparticles, (c) band gap of copper oxide nanoparticles. 


\subsection{Fourier transform infrared analysis.}

The FTIR spectra of the bio-integrated $\mathrm{CuO}$ nanoparticles are shown in Figure 5. FTIR is used to identify the functional groups of biomasses and the biomolecules bound to the surface of copper oxide nanoparticles. In addition, it shows precisely that a specific ceiling [36,37] . The peak at $3271 \mathrm{~cm}^{-1}$ is due to the $\mathrm{O}-\mathrm{H}$ bond stretching of alcohols and phenols [38]. The peak at $1234.44 \mathrm{~cm}^{-1}, 1444.68 \mathrm{~cm}^{-1}$ and $1384.89 \mathrm{~cm}^{-1}$ are attributed due to C-H out of smooth deformation and $\mathrm{C}-\mathrm{H}$ stretching vibration allocated due to the peak at $2960.73 \mathrm{~cm}^{-1}$ and $2827.74 \mathrm{~cm}^{-1}$. The height at $513 \mathrm{~cm}^{-1}$ indicates the formation of $\mathrm{CuO}$ nanostructure [39]. The absorption band at 1635.64 is due to $\mathrm{H}-\mathrm{O}-\mathrm{H}$ bending [40]. The aromatic ring $1535 \mathrm{~cm}^{-1}$ peak is present. Aliphatic amine group also present at $1063.13 \mathrm{~cm}^{-1}$ correlate with $\mathrm{C}-\mathrm{N}$ stretch [41].

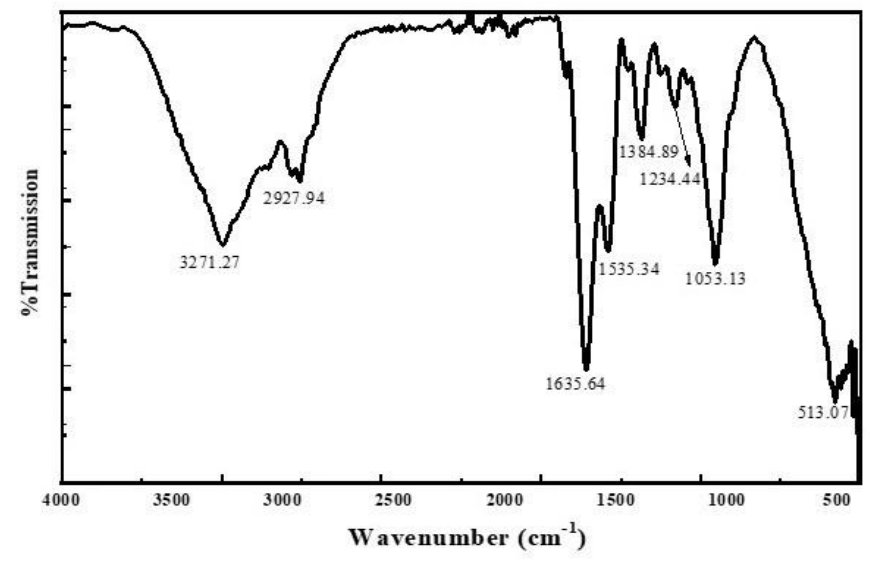

Figure 5. FTIR spectra for Copper oxide nanoparticle.
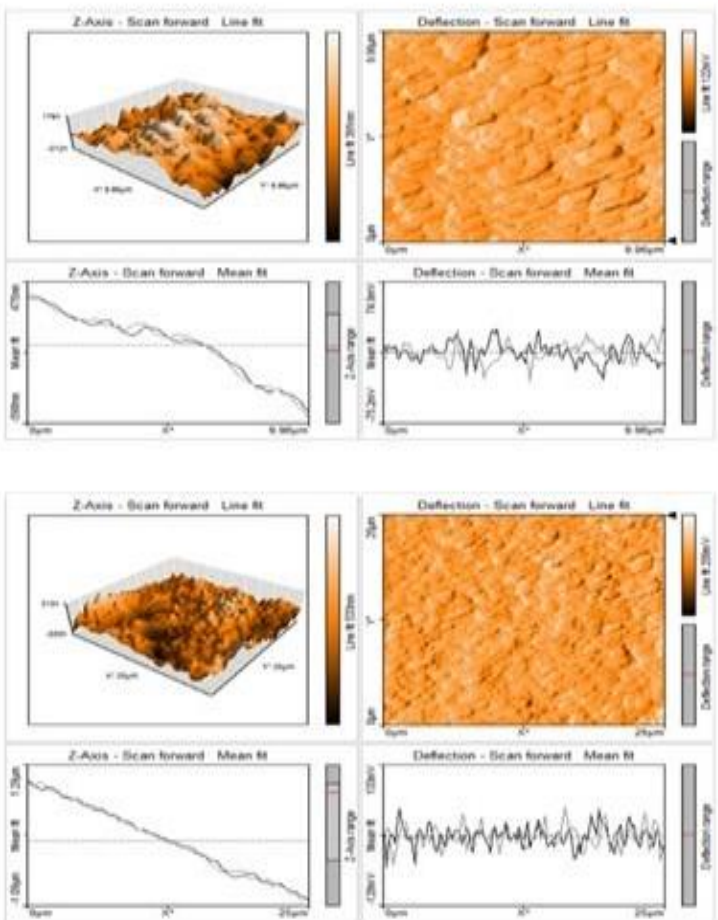
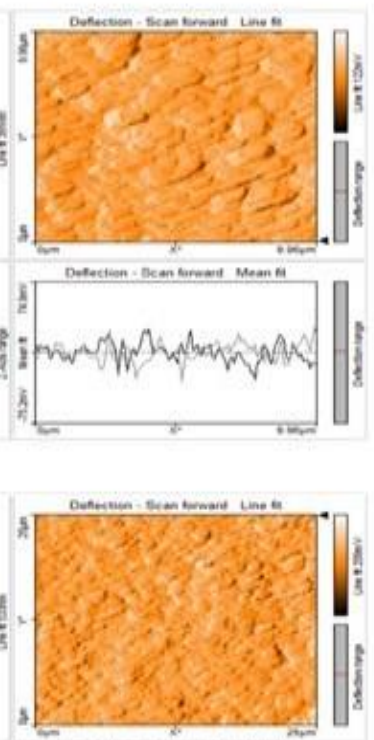

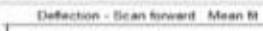

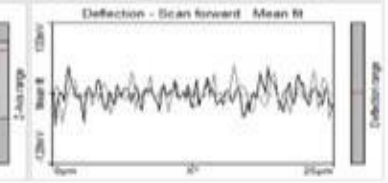

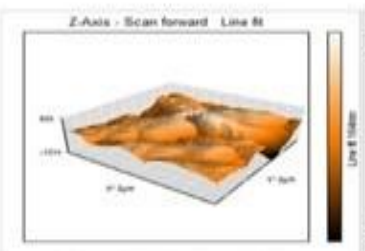
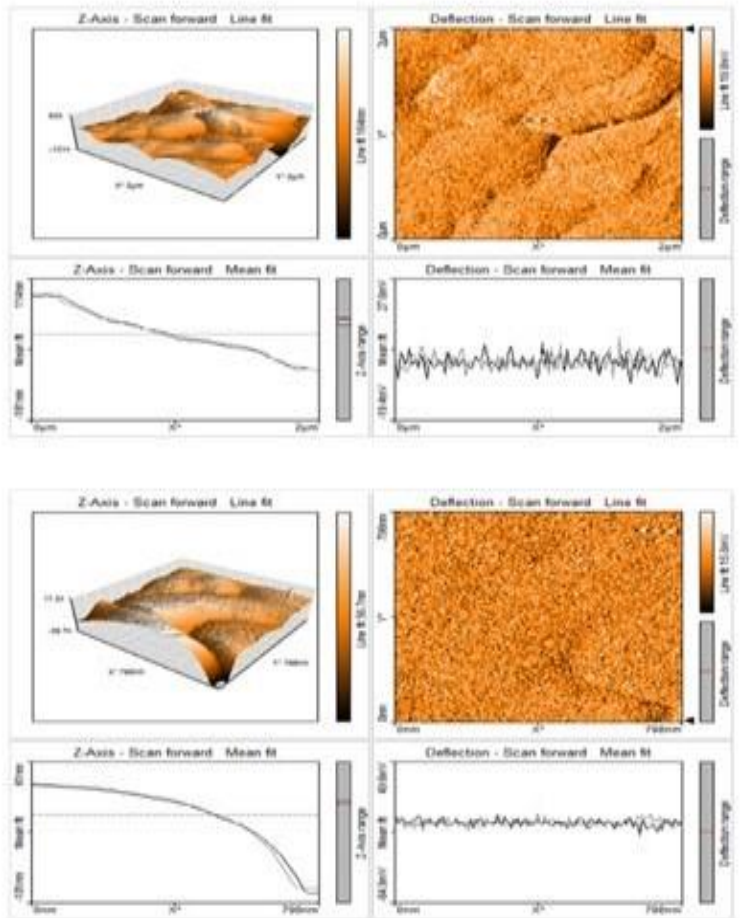

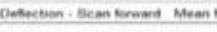

Figure 6. AFM image of synthesized copper nanoparticle (a) 2D and (b) 3D forms at different scan size.

\subsection{Surface topography analysis.}

The size of the $\mathrm{CuO}$ nanoparticles was measured by atomic force microscopy (AFM) in connection mode with silicon beams with energy constant $0.03-0.76 \mathrm{Nm}^{-1}$, Tip $10-15 \mu \mathrm{m}$ height. It also displays the image in 2-Dimension and 3-Dimension Figure 6 Show the copper 
nanoparticles with different scan size. Three-dimensional images in the particles were approximately spherical. 2D and 3D forms at different scan size and its surface area are given in Table 2. Also, it is demonstrated that exclusive restricted Nanostructures were estimated in AFM, the molecule measure is not an agent as that from dynamic light dispersing strategy and AFM is primarily utilized for morphology perception. The nanoparticles were steady in water and air did not change over into some additionally related mixes. Consequently, it occurs as profoundly scattered nanoparticles [42]. The AFM picture uncovers the high symmetric size of atoms with a fewer grouping of copper oxide nanoparticles. Particle shapes demonstrate the powerless accumulation of particles as a smooth line shape. The copper oxide nanoparticle shows an astounding propensity to frame uniform measured and formed agglomerates at less fixation.

\subsection{Toxicology study of the copper oxide nanoparticle using Zebrafish.}

The hatching rate of zebrafish embryos at $96 \mathrm{hpf}$ is exposed in Figure $7 \mathrm{a}, \mathrm{b}$ Altogether the embryos hatched effectively in the control group.
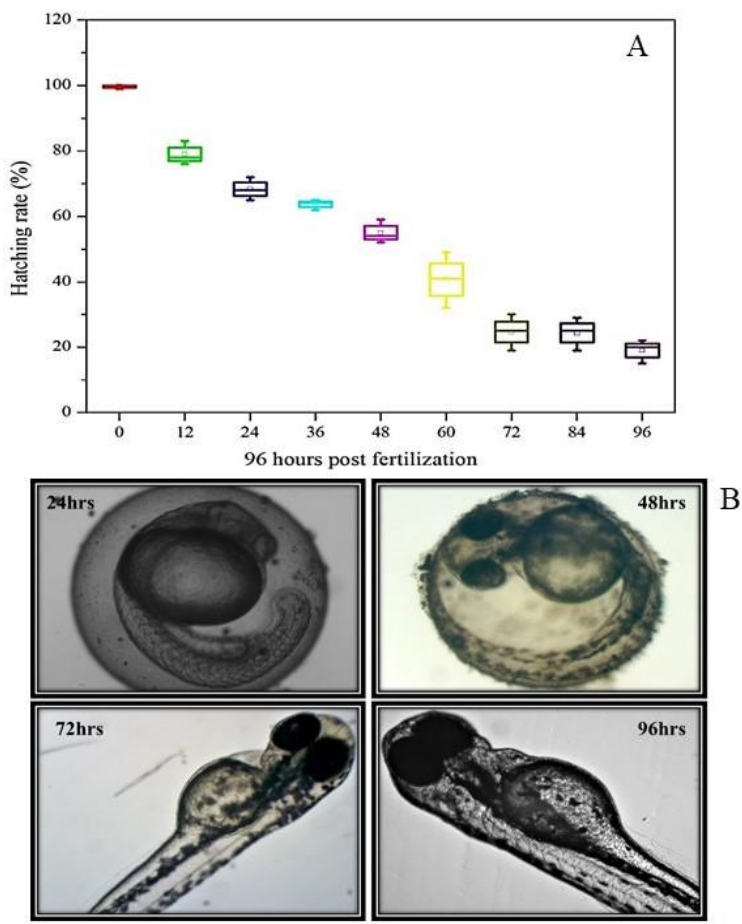

Figure 7. (A)Zebrafish embryo hatching rate after $24 \mathrm{~h}$ exposure to CuONPs at five different concentrations. (B)Hatchable presented as mean \pm SD based on three replicates.

The embryos hatched partially in the treated groups, and the hatching rate reduced with the increasing concentrations of CuONPs, the values of $\mathrm{LC}_{50}$ calculated from increasing hatching rates from 12 to $96 \mathrm{hpf}$. The results show that CuONPs treatment led to a significant increase in $\mathrm{LC}_{50}$, except $67.61 \mathrm{mg} / \mathrm{L} \mathrm{CuONPs,} \mathrm{LC50} \mathrm{was} \mathrm{not} \mathrm{calculated} \mathrm{because} \mathrm{of} \mathrm{the} \mathrm{hatching}$ rate of lower than $50 \%$. The minimum level of mortality of zebrafish embryo by exposed to $\mathrm{CuONPs}$ at $40 \mathrm{hpf}$. A substantial increase in death resulted in embryo exposed to CuONPs at $96 \mathrm{hpf}$, compared to the control [43]. Death of embryo exposed to CuONPs at these concentrations was also knowingly higher than for embryo exposed to CuONPs Figure 8a LC50 was approximately $67.61 \mathrm{mg} / \mathrm{L}$ for the CuONPs action, which equals $\approx 2 \mathrm{mg} \mathrm{Cu} \mathrm{L-1}$. Then mortality was low $(<10 \%)$ for the embryo in the $\mathrm{CuO}$ treatment Figure $8 \mathrm{~b}$. 

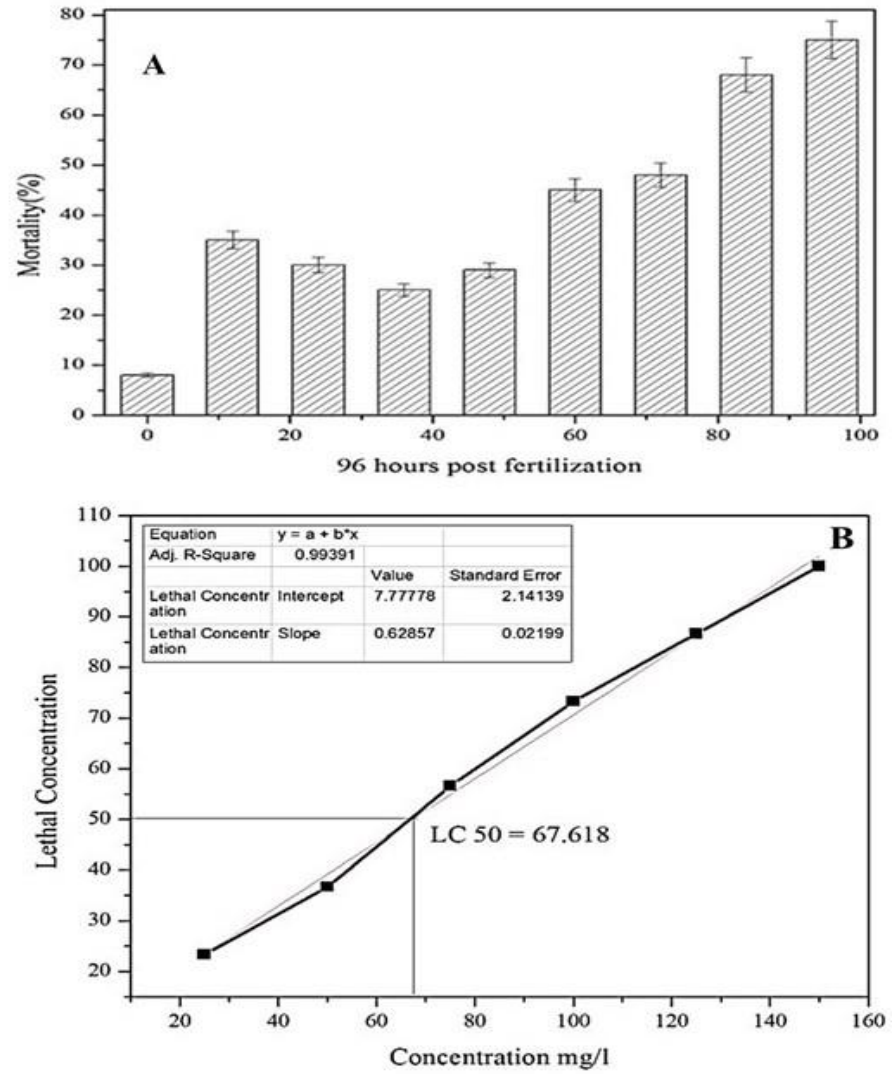

Figure 8. Zebrafish embryo cumulative percentage of mortality calculated after $72 \mathrm{~h}$ exposure to CuONPs at five different concentrations. (A) Mortality identified as mean \pm SD based on three replicates, (B) $\mathrm{LC}_{50}$ of $\mathrm{CuO}$ NPs for $96 \mathrm{~h}$ exposure.

Table 1. Structural Parameters of Copper oxide.

\begin{tabular}{|c|c|c|c|c|c|c|}
\hline Sample & $\begin{array}{l}\text { Lattice } \\
\text { parameter }\end{array}$ & $\begin{array}{l}\text { Volume } \\
\left(\mathbf{m}^{3}\right)\end{array}$ & $\begin{array}{l}\text { Particle } \\
\text { size(D) } \\
(\mathbf{n m})\end{array}$ & $\begin{array}{l}\text { Lattice Strain } \\
(\varepsilon) \\
\left(10^{-3}\right)\end{array}$ & $\begin{array}{l}\text { Dislocation } \\
\text { density }(\delta) \\
(\text { lines/cm } \\
\left(10^{15}\right) \\
\end{array}$ & $\begin{array}{l}\text { Surface area } \\
\text { (S) } \\
\mathrm{m}^{2} / \mathrm{g}\end{array}$ \\
\hline Copper oxide & 4.2016 & 74.1705 & 31.08 & 1.10 & 1.2635 & 54.045 \\
\hline
\end{tabular}

Table 2. AFM parameters at different scan size, surface area and surface roughness.

\begin{tabular}{c|l|l|l|l|l}
\hline Sample name & \multicolumn{1}{|c|}{ Scan size } & Setpoint force & \multicolumn{1}{c}{$\begin{array}{c}\text { Surface area } \\
\text { roughness (Sa) }\end{array}$} & $\begin{array}{c}\text { Surface area } \\
\text { roughness (sq) }\end{array}$ & Area Roughness \\
\hline \multirow{3}{*}{$\mathrm{CuO}$} & $2 \mu \mathrm{m}$ & $20 \mathrm{nN}$ & $14.897 \mathrm{~nm}$ & $20.196 \mathrm{~nm}$ & $4.047 \mathrm{pm}^{2}$ \\
\cline { 2 - 6 } & $10 \mu \mathrm{m}$ & $20 \mathrm{nN}$ & $52.004 \mathrm{~nm}$ & $64.65 \mathrm{~nm}$ & $100 \mathrm{pm}^{2}$ \\
\cline { 2 - 6 } & $25 \mu \mathrm{m}$ & $20 \mathrm{nN}$ & $58.061 \mathrm{~nm}$ & $75.063 \mathrm{~nm}$ & $629.9 \mathrm{pm}^{2}$ \\
\cline { 2 - 6 } & $800 \mathrm{~nm}$ & $20 \mathrm{nN}$ & $4.8605 \mathrm{~nm}$ & $6.9281 \mathrm{~nm}$ & $642.5 \mathrm{pm}^{2}$ \\
\hline
\end{tabular}

\section{Conclusions}

Synthesis of Copper oxide nanoparticles using microbes has been published in several papers. The need for commercially viable, financial and environment-friendly rote is still present to find the volume of a natural reducing constituent to form copper oxide nanoparticles. The CuONP that were bacterial-synthesised were found to be more stable with less ion release, this proved a new way to synthesize more environmentally friendly nanoparticles for various applications. Further research is needed to determine the cause of CuONP toxicity to action potential hazards to the biomedical and environment.

\section{Funding}

This research received no external funding. 


\section{Acknowledgments}

\section{The authors thank Vellore Institute of Technology, Vellore for providing "VIT SEED GRANT" for carrying out this research work.}

\section{Conflicts of Interest}

The authors declare no conflict of interest.

\section{References}

1. Grigore, M.E.; Biscu, E.R.; Holban, A.M.; Gestal, M.C.; Grumezescu, A.M. Methods of synthesis, properties and biomedical applications of $\mathrm{CuO}$ nanoparticles. Pharmaceuticals 2016, 9, 75, https://doi.org/10.3390/ph9040075.

2. Grasso, G.; Zane, D.; Dragone, R. Microbial nanotechnology: Challenges and prospects for green biocatalytic synthesis of nanoscale materials for sensoristic and biomedical applications. Nanomaterials 2020, 10, https://doi.org/10.3390/nano10010011.

3. Azam, A.; Ahmed, A.S.; Oves, M.; Khan, M.S.; Memic, A. Size-dependent antimicrobial properties of CuO nanoparticles against Gram-positive and -negative bacterial strains. International journal of nanomedicine 2012, 7, https://doi.org/10.2147/IJN.S29020.

4. Ponnar, M.; Thangamani, C.; Monisha, P.; Gomathi, S.S.; Pushpanathan, K. Influence of Ce doping on CuO nanoparticles synthesized by microwave irradiation method. Applied Surface Science 2018, 449, 132-143, https://doi.org/10.1016/j.apsusc.2018.01.126.

5. Ammaji, S.; Sunddepp, C.; Sandeep. K.; Ashok, Kunchala.; Praveen, K.; Murali, B.S. In silico toxicity prediction, synthesis, characterization, antimicrobial and antioxidant activity of different di substituted chalcones. Letters in Applied NanoBioScience 2020, 9, 908-913, https://doi.org/10.33263/LIANBS91.908913.

6. Singh, P.K.; Kumar, P.; Hussain, M.; Das, A.K.; Nayak, G.C. Synthesis and characterization of CuO nanoparticles using strong base electrolyte through electrochemical discharge process. Bulletin of Materials Science 2016, 39, 469-478, https://doi.org/10.1007/s12034-016-1159-1.

7. Jillani, S.; Jelani, M.; Hassan, N.U.; Ahmad, S.; Hafeez, M. Synthesis, characterization and biological studies of copper oxide nanostructures. Materials Research Express 2018, 5.

8. Chatterjee, A.K.; Sarkar, R.K.; Chattopadhyay, A.P.; Aich, P.; Chakraborty, R.; Basu, T. A simple robust method for synthesis of metallic copper nanoparticles of high antibacterial potency against E. coli. Nanotechnology 2012, 23.

9. Sharma, G.; Jasuja, N.D.; Kumar, M.; Ali, M.I. Biological synthesis of silver nanoparticles by cell-free extract of spirulina platensis. Journal of Nanotechnology 2015, 2015, https://doi.org/10.1155/2015/132675.

10. Saran, S.; Sharma, G.; Kumar, M.; Ali, M.I. Biosynthesis of copper oxide nanoparticles using cyanobacteria spirulina platensis and its antibacterial activity. International Journal of Pharmaceutical Sciences and Research 2017, 8, 3887-3892, https://doi.org/10.13040/IJPSR.0975-8232.

11. Vishnu, S.; Ramaswamy, P.; Narendhran, S.; Sivaraj, R. Potentiating effect of ecofriendly synthesis of copper oxide nanoparticles using brown alga: antimicrobial and anticancer activities. Bulletin of Materials Science 2016, 39, 361-364, https://doi.org/10.1007/s12034-016-1173-3.

12. Han, W.K.; Choi, J.W.; Hwang, G.H.; Hong, S.J.; Lee, J.S.; Kang, S.G. Fabrication of Cu nano particles by direct electrochemical reduction from CuO nano particles. Applied Surface Science 2006, 252, 2832-2838, https://doi.org/10.1016/j.apsusc.2005.04.049.

13. Ullah, A.; Ullah, N.; Rasheed, S. Green synthesis of copper nanoparticles using extract of Dicliptera Roxburghiana, their characterization and photocatalytic activity against methylene blue degradation. Letters in Applied NanoBioScience 2020, 9, 897-901, https://doi.org/10.33263/LIANBS91.897901.

14. Ullah, H.; Israr, M. The antioxidant activity and phytochemical analysis of medicinal plant Veronica biloba. Letters in Applied NanoBioScience 2019, 8, 732-738, https://doi.org/10.33263/LIANBS84.732738.

15. Yallappa, S.; Manjanna, J.; Sindhe, M.A.; Satyanarayan, N.D.; Pramod, S.N.; Nagaraja, K. Microwave assisted rapid synthesis and biological evaluation of stable copper nanoparticles using T. arjuna bark extract. Spectrochimica Acta Part A: Molecular and Biomolecular Spectroscopy 2013, 110, 108-115, https://doi.org/10.1016/j.saa.2013.03.005.

16. Kiessling, F.; Liu, Z.; Gätjens, J. Advanced nanomaterials in multimodal imaging: Design, functionalization, and biomedical applications. Journal of Nanomaterials 2010, 2010, https://doi.org/10.1155/2010/894303.

17. Deryabin, D.G.; Aleshina, E.S.; Vasilchenko, A.S.; Deryabina, T.D.; Efremova, L. V; Karimov, I.F.; Korolevskaya, L.B. Investigation of Copper Nanoparticles Antibacterial Mechanisms Tested by Luminescent Escherichia coli Strains. Nanotechnologies in Russia 2013, 8, 402-408, https://doi.org/10.1134/S1995078013030063. 
18. Kalatehjari, P.; Yousefian, M.; Khalilzadeh, M.A. Assessment of antifungal effects of copper nanoparticles on the growth of the fungus Saprolegnia sp. on white fish (Rutilus frisii kutum) eggs. The Egyptian Journal of Aquatic Research 2015, 41, 303-306, https://doi.org/10.1016/j.ejar.2015.07.004.

19. Palashuddin S.M.; Goswami, U.; Ghosh, S.S.; Chattopadhyay, A. Cu 2+-embedded carbon nanoparticles as anticancer agents. Journal of Materials Chemistry $B \quad \mathbf{2 0 1 5}, \quad 3, \quad 5673-5677$, https://doi.org/10.1039/C5TB00567A.

20. Usha, S.; Ramappa, K.T.; Hiregoudar, S.; Vasanthkumar, G.D.; Aswathanarayana, D.S. Biosynthesis and Characterization of Copper Nanoparticles from Tulasi (Ocimum sanctum L.) Leaves. International Journal of Current Microbiology and Applied Sciences 2017, 6, 2219-2228, https://doi.org/10.20546/ijcmas.2017.611.263.

21. Ghosh, P.R.; Fawcett, D.; Sharma, S.B.; Poinern, G.E.J. Production of high-value nanoparticles via biogenic processes using aquacultural and horticultural food waste. Materials 2017, 10, 852, https://doi.org/10.3390/ma10080852.

22. Singaravelu, G.; Arockiamary, J.S.; Kumar, V.G.; Govindaraju, K. A novel extracellular synthesis of monodisperse gold nanoparticles using marine alga, Sargassum wightii Greville. Colloids and surfaces B: Biointerfaces 2007, 57, 97-101, https://doi.org/10.1016/j.colsurfb.2007.01.010.

23. Thakkar, K.N.; Mhatre, S.S.; Parikh, R.Y. Biological synthesis of metallic nanoparticles. Nanomedicine: nanotechnology, biology and medicine 2010, 6, 257-262, https://doi.org/10.1016/j.nano.2009.07.002.

24. Sintubin, L.; Verstraete, W.; Boon, N. Biologically produced nanosilver: Current state and future perspectives. Biotechnology and Bioengineering 2012, 109, 2422-2436, https://doi.org/10.1002/bit.24570.

25. Caballero, M.V.; Candiracci, M. Zebrafish as Toxicological model for screening and recapitulate human diseases. Journal of Unexplored Medical Data 2018, 3, https://doi.org/10.20517/2572-8180.2017.15.

26. Kaur, J.; Khatri, M.; Puri, S. Toxicological evaluation of metal oxide nanoparticles and mixed exposures at low doses using zebra fish and THP1 cell line. Environmental toxicology 2019, 34, 375-387, https://doi.org/10.1002/tox.22692.

27. Xu, J.; Zhang, Q.; Li, X.; Zhan, S.; Wang, L.; Chen, D. The effects of copper oxide nanoparticles on dorsoventral patterning, convergent extension, and neural and cardiac development of zebrafish. Aquatic Toxicology 2017, 188, 130-137, https://doi.org/10.1016/j.aquatox.2017.05.002.

28. Guidelines, O.; The, F.O.R.; Of, T. Test No. 236: Fish Embryo Acute Toxicity (FET) Test 2013, 1-22, https://doi.org/10.1787/20745761.

29. OECD Test Guideline 203. Fish, Acute Toxicity Test. OECD Guidelines for the Testing of Chemicals 2019, 1-23, https://doi.org/10.1787/20745788.

30. Griffitt, R.J.; Weil, R.; Hyndman, K.A.; Denslow, N.D.; Powers, K.; Taylor, D.; Barber, D.S. Exposure to copper nanoparticles causes gill injury and acute lethality in zebrafish (Danio rerio). Environmental science \& technology 2007, 41, 8178-8186. https://doi.org/10.1021/es071235e.

31. Jayaprakash, J.; Srinivasan, N.; Chandrasekaran, P. Surface modifications of CuO nanoparticles using Ethylene diamine tetra acetic acid as a capping agent by sol-gel routine. Spectrochimica Acta Part A: Molecular and Biomolecular Spectroscopy 2014, 123, 363-368, https://doi.org/10.1016/j.saa.2013.12.080.

32. Felix, S.; Chakkravarthy, R.B.P.; Grace, A.N. Microwave assisted synthesis of copper oxide and its application in electrochemical sensing. In IOP Conference Series: Materials Science and Engineering 2015, 73, https://doi.org/10.1088/1757-899X/73/1/012115.

33. Padil, V.V.T.; Černík, M. Green synthesis of copper oxide nanoparticles using gum karaya as a bio template and their antibacterial application. International journal of nanomedicine 2013, 8 , https://doi.org/10.2147/IJN.S40599.

34. Kayani, Z.N.; Umer, M.; Riaz, S.; Naseem, S. Characterization of Copper Oxide Nanoparticles Fabricated by the Sol-Gel Method. Journal of Electronic Materials 2015, 44, 3704-3709, https://doi.org/10.1007/s11664-015-3867-5

35. Nabila, M.I.; Kannabiran, K. Biosynthesis, characterization and antibacterial activity of copper oxide nanoparticles (CuO NPs) from actinomycetes. Bio catalysis and agricultural biotechnology 2018, 15, 5662, https://doi.org/10.1016/j.bcab.2018.05.011.

36. Rodriguez-Chanfrau, J.; E., Rodriguez-Riera, Z.; Gamiotea-Turro, D. Trimethylchitosan hydrochloride obtained from lobster carapace chitin on a bench scale. Biointerface Research in Applied Chemistry 2019,9, 4279-4283, https://doi.org/10.33263/BRIAC95.279283.

37. Hassabo, A. G.; Sharaawy, S.; Mohamed, A. L. Novel flame retardant and antibacterial agent containing $\mathrm{MgO}$ NPs, phosphorus, nitrogen and silicon units for functionalise cotton fabrics. Biointerface Research in Applied Chemistry 2019,9, 4272-4278, https://doi.org/10.33263/BRIAC95.272278

38. Abdul Majeed, A.M.; Abd, A.N.; Hussein, A.A.; Habubi, N.F. Fabrication and Characterization of Copper Oxide Nanoparticles/PSi Hetero diode. International Letters of Chemistry, Physics and Astronomy 2015, 57, 25-35.

39. Badetti, E.; Calgaro, L.; Falchi, L.; Bonetto, A.; Bettiol, C.; Leonetti, B.; Ambrosi, E.; Zendri, E.; Marcomini, A. Interaction between copper oxide nanoparticles and amino acids: Influence on the antibacterial activity. Nanomaterials 2019, 9, https://doi.org/10.3390/nano9050792. 
40. Buazar, F.; Sweidi, S.; Badri, M.; Kroushawi, F. Biofabrication of highly pure copper oxide nanoparticles using wheat seed extract and their catalytic activity: A mechanistic approach. Green Processing and Synthesis 2019, 8, 691-702, https://doi.org/10.1515/gps-2019-0040.

41. Uddandarao, P.; Balakrishnan, R.M. Thermal and optical characterization of biologically synthesized ZnS nanoparticles synthesized from an endophytic fungus Aspergillus flavus: A colorimetric probe in metal detection. Spectrochimica Acta Part A: Molecular and Biomolecular Spectroscopy 2017, 175, 200-207, https://doi.org/10.1016/j.saa.2016.12.021.

42. Singh, R.K.; Knowles, J.C.; Kim, H.W. Advances in nanoparticle development for improved therapeutics delivery: nanoscale topographical aspect. Journal of tissue engineering 2019, 10, https://doi.org/10.1177/2041731419877528.

43. Chakraborty, C.; Sharma, A.R.; Sharma, G.; Lee, S.S. Zebrafish: A complete animal model to enumerate the nanoparticle toxicity. Journal of nanobiotechnology 2016, 14, https://doi.org/10.1186/s12951-016-0217-6. 